\title{
Bezlotoxumab: an emerging monoclonal antibody therapy for prevention of recurrent Clostridium difficile infection
}

This article was published in the following Dove Press journal: Biologics:Targets and Therapy

\author{
Bhagyashri D Navalkele' \\ Teena Chopra ${ }^{2}$ \\ 'Internal Medicine and Infectious \\ Diseases, University of Mississippi \\ Medical Center, Jackson, MS, USA; \\ ${ }^{2}$ Internal Medicine and Infectious \\ Diseases, Infection Prevention and \\ Epidemiology, Detroit Medical Center, \\ Wayne State University, Detroit, MI, \\ USA
}

\begin{abstract}
Clostridium difficile infection (CDI) is the most common health care-acquired infection associated with high hospital expenditures. The incidence of subsequent recurrent CDI increases with prior episodes of CDI, $15 \%-35 \%$ risk after primary CDI to $35 \%-65 \%$ risk after the first recurrent episode. Recurrent CDI is one of the most challenging and a very difficult to treat infections. Standard guidelines provide recommendations on treatment of primary CDI. However, treatment choices for recurrent CDI are limited. Recent research studies have focused on the discovery of newer alternatives for prevention of recurrent CDI targeting prime virulence factors involved in $C$. difficile pathogenesis. Bezlotoxumab is a human monoclonal antibody directed against $C$. difficile toxin B. Multiple in vitro and in vivo animal studies have demonstrated direct binding of bezlotoxumab to $C$. difficile toxin B preventing intestinal epithelial damage and colitis. Furthermore, this monoclonal antibody mediates early reconstitution of gut microbiota preventing risk of recurrent CDI. Randomized placebo-controlled trials showed concomitant administration of a single intravenous dose of $10 \mathrm{mg} / \mathrm{kg}$ of bezlotoxumab, in patients on standard-of-care therapy for CDI, had no substantial effect on clinical cure rates but significantly reduced the incidence of recurrent CDI ( $40 \%$ ). It shows efficacy against multiple strains, including the epidemic BI/NAP1/027 strain. Bezlotoxumab is a US Food and Drug administration-approved, safe and well-tolerated drug with low risk of serious adverse events and drug-drug interactions. Bezlotoxumab has emerged as a novel dynamic adjunctive therapy for prevention of recurrent CDI. Further studies on real-world experience with bezlotoxumab and its impact in reducing rates of recurrent CDI are needed.
\end{abstract}

Keywords: bezlotoxumab, Clostridium difficile, monoclonal antibody, novel CDI treatment, anti-toxin B antibody, prevention of recurrent CDI

\section{Introduction}

Clostridium difficile, a spore-forming anaerobic gram-positive bacillus, causes infections ranging from mild diarrhea to severe complicated disease. Clostridium difficile infection (CDI) is recognized as a leading cause of hospital-onset infection. ${ }^{1}$ Lately, increasing incidences of CDI are being reported from other settings such as the community, long-term care facilities, and nursing homes. ${ }^{2}$

After the initial episode of CDI, the risk for recurrent infections increases exponentially. Of the nearly 500,000 CDIs in the USA in 2011, approximately $1 \%$ developed at least one episode of recurrent CDI. ${ }^{3}$ Subsequently, the risk of further recurrences following the first recurrent CDI is estimated to range from $35 \%$ to $65 \%{ }^{4,5} \mathrm{CDI}$ is associated with varied mortality rates of $3 \%-36 \% .{ }^{5}$ On the contrary, recurrent CDI is associated with $33 \%$ higher mortality risk and 2.5 -fold higher hospital readmission rate. ${ }^{5}$
Correspondence: Bhagyashri D Navalkele University of Mississippi Medical Center, 2500 North State St, Jackson, MS 39216, USA

Tel +l 60I 9845560

$\mathrm{Fax}+\mathrm{I} 6019845565$

Email b.navalkele@gmail.com 
In 2008, acute care facilities were estimated to spend approximately US\$4.8 billion in health care expenditures for the management of hospital-onset-CDI. ${ }^{4} \mathrm{~A}$ model-framework study by Desai et al estimated $87 \%$ of CDI expenditure in 2014 (US\$4.7 billion) to be related to acute care hospitalizations, long-term acute care, and long-term care facility costs. The study reported lower costs (US\$725 million) in the management of CDI in the community. ${ }^{5}$ Per study analysis, $33 \%$ of the total CDI expenditure in a health care facility is devoted to the management of recurrent CDI (US\$1.5/4.7 billion). A retrospective study performed in Canada from 1998 to 2013 reported $9 \%$ of CDI patients developed multiple $(\geq 2)$ recurrent CDI $(128 / 1389) .{ }^{6}$ In the recurrent CDI subset population $(n=434)$, $34 \%$ of patients required hospitalization for the management of recurrent episode. The total cost of hospitalization in patients with recurrent CDI was estimated to be US\$6,500 per day. The real-world prevalence of CDI and its related expenditure in the non-acute care setting remains undetermined. Thus, the true health care burden of CDI remains unknown.

The key objectives in management of CDI are clinical cure and prevention of recurrent CDI. Limited management strategies exist to prevent these recurrent episodes. Bezlotoxumab is a novel monoclonal antibody against $C$. difficile toxin B approved for prevention of recurrent CDI. Here, we provide a detailed review on CDI pathogenesis, the current available CDI treatment options, and on bezlotoxumab outlining its pharmacology, mechanism of action, efficacy data, and safety evidence.

\section{CDI pathogenesis \\ Bacterial pathogenesis}

Introduction of spores via fecal-oral route is the first step in intestinal colonization and infection with $C$. difficile. C. difficile spores are infective particles harboring the dormant form of $C$. difficile bacteria. They play a crucial role in infection and transmission of CDI. C. difficile spores are resistant to heat, radiation, and alcohol-based disinfection resulting in environmental persistence. Fecal shedding of spores by symptomatic and asymptomatic $C$. difficile carrier patients causes rapid spread of this disease. Spores travel through the stomach into the small intestine where under optimal conditions (higher cholate-containing bile salts and lower chenodeoxycholic acids) germination of spores results in formation of the vegetative cells. ${ }^{7}$ These vegetative cells then colonize and proliferate in the colon marking the onset of CDI.

The severe pathogenesis of CDI is regulated by expression of genes located on the pathogenicity locus controlling the major functions of toxin production (toxin A and B genes), toxin expression (toxin R), toxin release (toxin E), and toxin synthesis (toxin C). ${ }^{7}$

Of all the virulence factors attributed to CDI, toxin production is the most significant factor. ${ }^{8}$ Non-pathogenic C. difficile strains produce spores but do not cause symptomatic infection in animals or humans. Infection with pathogenic strains results in toxin production from the vegetative cells leading to CDI. Toxin A and toxin B are the two pathogenic toxins involved in CDI. Toxins act by binding to the intestinal epithelial cells, undergoing endocytosis, and then forming pores in the epithelial cells. Toxins also inactivate the Rho proteins, which regulate actin depolymerization and maintain structural integrity of the cell. ${ }^{8}$ This inactivation has a cytopathic effect on the colonic wall increasing its permeability and apoptosis leading to diarrhea. Toxin-related cytotoxic effects are seen secondary to activation of inflammatory markers producing colitis and severe CDI. Besides intestinal effects, there is evidence of toxin-mediated extraintestinal damage causing neurotoxicity, cardiotoxicity, and nephrotoxicity. ${ }^{8}$

Multiple animal studies reported toxin A as the major virulence factor associated with severe inflammatory response and intestinal damage in CDI. ${ }^{9}$ Immunization against toxin A, not toxin $\mathrm{B}$, in hamster models was protective against C. difficile colitis. Toxin B was reported to be functionally dependent on toxin A-related intestinal damage to produce cytotoxic effect on intestinal epithelial cells. However, recent numerous animal studies have published the independent pathogenicity of toxin $\mathrm{B}$, now recognized as the major toxin in CDI. ${ }^{10}$ Toxin B resulted in higher inflammatory response, severe damage to colonic wall, systemic CDI, and higher mortality in the hamster models compared to toxin A. ${ }^{11}$ Thus, most of the ongoing research studies are focused on the discovery of agents targeted against $C$. difficile toxin B.

Strain typing has led to the identification of numerous geographically and genetically diverse strains of $C$. difficile. Multiple CDI outbreaks in the low risk population of the USA, UK, and Canada have led to the discovery of hypervirulent strain of $C$. difficile identified as the BI/NAP1/027 strain. ${ }^{5,12}$ The widespread use of fluoroquinolones was correlated to the rapid spread of this epidemic strain harboring intrinsic fluoroquinolone resistance. The epidemic strains frequently cause severe CDI. This infectious property is secondary to the higher amounts of toxin production by epidemic strains than wild type strains and the production of variant toxin B potentiating its cytotoxicity. ${ }^{13}$ Other than the role of toxin A and B in CDI pathogenesis, the binary toxin, $C$. difficile transferases, has been recognized as an additional virulence factor, especially 
in the BI/NAP1/027 strain. ${ }^{14}$ The binary toxin is presumed to aid in adherence and colonization of $C$. difficile. Its complete role in the pathogenesis is still undetermined.

Other non-toxin related virulence factors involved in CDI pathogenesis act by increasing its adhesion to the cell wall. Cell wall proteins, fibronectin-binding proteins, heatshock proteins found in $C$. difficile and polysaccharides in the vegetative cells, support adhesion of $C$. difficile to the intestinal epithelial cells promoting its colonic invasion and colonization. ${ }^{14}$ Fimbriae and flagella in $C$. difficile also aid in adhesion and intestinal colonization, however its exact role remains controversial due to its inconsistent detection in different $C$. difficile isolates. ${ }^{14}$

\section{Host defense}

Natural host defenses against infection from $C$. difficile are provided by the gut microbiota. ${ }^{15}$ However, disruption in the normal gastrointestinal microbiota, predominantly seen after treatment with antibiotic therapy, serves as a foundation for unrepressed $C$. difficile colonization and infection.

During the infective period, humoral immune response is generated against $C$. difficile resulting in the production of endogenous antitoxin antibodies to fight against $C$. difficile toxin A and B. Lower serum antitoxin antibody levels have been linked to the development of severe and recurrent CDI. ${ }^{16,17}$ In humans, use of intravenous antitoxin antibodies has led to suppression of CDI symptoms. Vaccination against toxin A and B in patients with relapsing CDI has successfully reduced the relapse rates. ${ }^{18}$ In vitro study on human colonic explants and peripheral blood monocyte cell cultures showed diminished inflammatory response and colonic inflammation in presence of the antitoxin antibody against $C$. difficile toxin A and B. ${ }^{19}$ Thus, published research studies have established the crucial role of antitoxin antibodies in protecting against the deleterious effects of CDI.

\section{Current treatment options for CDI}

Discontinuation of ongoing antibiotic therapy is the best strategy in the treatment of CDI. However, as stopping the antibiotic therapy is not always feasible, specific anti-CDI treatment is recommended in the management of CDI. Metronidazole is the first-line choice in treatment of primary non-severe CDI, however there is growing evidence of higher metronidazole resistance and lower clinical success with metronidazole in comparison to vancomycin. ${ }^{2,20,21}$ Currently, vancomycin is the preferred oral antibiotic for treatment of both primary and recurrent CDI. Dual antibiotic therapy with metronidazole and vancomycin has been recommended for treatment of severe complicated CDI. ${ }^{1}$ Unfortunately, vancomycin and metronidazole have both demonstrated ability to disrupt the colonic microbiota limiting its efficacy in prevention of recurrent CDI. ${ }^{21}$ Fidaxomicin is a potent antibiotic therapy option with minimal risk of damage to colonic flora, providing sustained cure rates in CDI. ${ }^{22}$ However, weak evidence in treatment of life-threatening disease and high drug cost have limited its application. Multiple newer antibiotics with activity against $C$. difficile are currently under trial. ${ }^{23}$

Substantial evidence supports the use of fecal microbiota transplant (FMT) in prevention of recurrent CDI. ${ }^{23}$ The European Society of Clinical Microbiology and Infectious diseases guidelines recommend the use of FMT as nonantibiotic therapy of choice for the management of recurrent CDI. ${ }^{21}$ Unfortunately, FMT continues to be an experimental procedure awaiting formal recommendation for use in CDI treatment guidelines in the USA.

Apart from treatment options, there has been an increasing focus on prevention of CDI to reduce the health care burden. The use of probiotics in prevention of CDI remains controversial. Multiple randomized controlled trials and meta-analyses studies have demonstrated the potential benefit of probiotics, especially in patients with recurrent CDI or with primary CDI on concurrent antibiotics. ${ }^{21}$ Lack of strong quality evidence limits the use of probiotics in prevention of CDI. Clinical trials involving vaccines against $C$. difficile toxins, antitoxin immunoglobulin therapy, and use of nontoxigenic $C$. difficile strains are currently underway to evaluate its effectiveness in prevention of CDI. ${ }^{23,24}$ The efficacy of supplemental anti-CDI prophylaxis therapy (ribaxamase, DAV132) during antibiotic treatment of non-CDI related sepsis is being studied, with the goal to minimize antibiotic exposure and retain normal gut microbiota. ${ }^{23}$

Among preventive therapies, treatment with monoclonal antibody against $C$. difficile toxin $\mathrm{A}$ and toxin $\mathrm{B}$ has been evaluated in clinical trials to prevent recurrent CDI. Even though actoxumab (antitoxin A monoclonal antibody) failed to demonstrate efficacy in prevention of recurrent disease, bezlotoxumab (antitoxin B monoclonal antibody) has shown promising results. ${ }^{25}$ A summary on current and emerging management options for CDI is illustrated in Table 1.

\section{Structure and mechanism of action}

Bezlotoxumab is a fully humanized IgG1/kappa monoclonal antibody of $148 \mathrm{kDa}$ molecular weight. ${ }^{26}$ An experimental study was conducted to understand the structure of bezlotoxumab bound to the toxin B. ${ }^{27}$ In this study, Western blot, temperature-dependent fluorescence, hydrogen deuterium 
Table I Current and emerging treatment and preventive options in Clostridium difficile infection

\begin{tabular}{|c|c|c|c|c|c|}
\hline \multirow{2}{*}{$\begin{array}{l}\text { Antimicrobial/ } \\
\text { Non- } \\
\text { antimicrobial } \\
\text { agents }\end{array}$} & \multirow[t]{2}{*}{$\begin{array}{l}\text { Recommended } \\
\text { dosage and duration }\end{array}$} & \multirow[t]{2}{*}{ Role in CDI } & \multicolumn{2}{|c|}{$\begin{array}{l}\text { Current guidelines } \\
\text { recommendation }\end{array}$} & \multirow[t]{2}{*}{ Comments } \\
\hline & & & $\begin{array}{l}\text { SHEA-IDSA } \\
2010\end{array}$ & $\begin{array}{l}\text { ESCMID }^{21} \\
2014\end{array}$ & \\
\hline \multicolumn{6}{|c|}{ Current treatment options } \\
\hline Metronidazole & $\begin{array}{l}500 \mathrm{mg} \text { orally or } \\
\text { intravenous thrice daily } \\
\text { for } 10-14 \text { days }\end{array}$ & $\begin{array}{l}\text { Initial episode, mild- } \\
\text { moderate } \\
\text { Initial episode, severe, } \\
\text { complicated } \\
\text { Multiple recurrences }\end{array}$ & $\begin{array}{l}\text { A-I } \\
- \\
-\end{array}$ & $\begin{array}{l}\text { A-I } \\
\text { A-II (IV) } \\
\text { D-I } \\
\text { D-II }\end{array}$ & $\begin{array}{l}\text { Non-FDA approved. Bactericidal } \\
\text { activity against } C \text {. difficile. Increasing } \\
\text { reports of } C \text {. difficile resistance. }\end{array}$ \\
\hline Vancomycin & $\begin{array}{l}\text { I } 25 \mathrm{mg} \text { orally four } \\
\text { times a day for } 10-14 \\
\text { days } \\
500 \mathrm{mg} \text { orally four times } \\
\text { daily for } 10 \text { days } \\
\text { Taper/pulsed regimen }\end{array}$ & $\begin{array}{l}\text { Initial episode, severe } \\
\text { Initial episode, severe } \\
\text { or complicated } \\
\text { Multiple recurrence }\end{array}$ & $\begin{array}{l}\text { B-I } \\
- \\
\text { B-III }\end{array}$ & $\begin{array}{l}\text { A-I } \\
\text { B-III } \\
\text { B-II }\end{array}$ & $\begin{array}{l}\text { FDA approved. Bactericidal activity } \\
\text { against } C \text {. difficile. Current preferred } \\
\text { treatment of choice. }\end{array}$ \\
\hline $\begin{array}{l}\text { Vancomycin with } \\
\text { metronidazole }\end{array}$ & $\begin{array}{l}500 \mathrm{mg} \text { orally or } \\
\text { rectally (in ileus) } \\
\text { four times a day } \\
\text { with metronidazole } \\
\text { intravenous } 500 \mathrm{mg} \\
\text { thrice daily }\end{array}$ & $\begin{array}{l}\text { Initial episode, severe- } \\
\text { complicated }\end{array}$ & C-III & $\begin{array}{l}\text { A-II } \\
\text { (metronidazole) } \\
\text { B-III } \\
\text { (vancomycin) }\end{array}$ & \\
\hline Fidaxomicin & $\begin{array}{l}200 \mathrm{mg} \text { orally twice } \\
\text { daily for } 10 \text { days }\end{array}$ & $\begin{array}{l}\text { Initial episode, mild- } \\
\text { moderate } \\
\text { Initial episode, severe } \\
\text { (Risk of) First recurrent } \\
\text { episode } \\
\text { Life-threatening CDI } \\
\text { Multiple recurrent } \\
\text { episodes }\end{array}$ & $\begin{array}{l}- \\
- \\
- \\
- \\
-\end{array}$ & $\begin{array}{l}\text { B-I } \\
\text { B-I } \\
\text { B-I } \\
\text { D-III } \\
\text { B-II }\end{array}$ & $\begin{array}{l}\text { FDA approved. Macrolide antibiotic } \\
\text { with narrow spectrum activity. }\end{array}$ \\
\hline $\begin{array}{l}\text { Fecal microbiota } \\
\text { transplant }\end{array}$ & $\begin{array}{l}\text { Administered along } \\
\text { with oral antibiotic } \\
\text { therapy }\end{array}$ & Multiple recurrences & - & $A-I$ & $\begin{array}{l}\text { Restores normal microbiota. } \\
\text { Investigational drug in the USA. }\end{array}$ \\
\hline Tigecycline & $\begin{array}{l}50 \mathrm{mg} \text { intravenous } \\
\text { twice daily for } 14 \text { days }\end{array}$ & Severe episode & - & C-III & $\begin{array}{l}\text { Non-FDA approved. Protein synthesis } \\
\text { inhibitor activity against } C \text {. difficile } \\
\text { toxins and spores. Small case studies } \\
\text { support its use when treatment with } \\
\text { oral therapy is not possible. }\end{array}$ \\
\hline Nitazoxanide & $\begin{array}{l}500 \mathrm{mg} \text { oral twice daily } \\
\text { for } 10 \text { days }\end{array}$ & Initial CDI & - & - & $\begin{array}{l}\text { Bactericidal activity against CDI. No } \\
\text { formal recommendation on use. }\end{array}$ \\
\hline Rifaximin & $\begin{array}{l}400 \mathrm{mg} \text { oral twice daily } \\
\text { for } 10-14 \text { days }\end{array}$ & $\begin{array}{l}\text { Initial and recurrent } \\
\mathrm{CDI}\end{array}$ & - & - & $\begin{array}{l}\text { Follow-up therapy after completion } \\
\text { of vancomycin. Reports on risk for } \\
\text { resistance during treatment. No } \\
\text { formal recommendation on use. }\end{array}$ \\
\hline Teicoplanin & $\begin{array}{l}400 \mathrm{mg} \text { oral twice daily } \\
\text { for } 10 \text { days }\end{array}$ & Initial CDI & - & - & $\begin{array}{l}\text { Similar efficacy to vancomycin. } \\
\text { Indicated as an alternative treatment } \\
\text { option for CDI. Not available in the } \\
\text { USA. No formal recommendation } \\
\text { on use. }\end{array}$ \\
\hline Bacitracin & $\begin{array}{l}20,000-25,000 \text { units } \\
\text { orally four times daily } \\
\text { for } 7-10 \text { days }\end{array}$ & Initial CDI & - & - & $\begin{array}{l}\text { Lower efficacy, higher risk of } \\
\text { CDI recurrence. No formal } \\
\text { recommendation on use. }\end{array}$ \\
\hline Fusidic acid & $\begin{array}{l}250 \mathrm{mg} \text { oral thrice daily } \\
\text { for } 7-10 \text { days }\end{array}$ & Initial CDI & - & - & $\begin{array}{l}\text { Lower efficacy, higher risk of } \\
\text { CDI recurrence. No formal } \\
\text { recommendation on use. }\end{array}$ \\
\hline Tolevamer & $3 \mathrm{~g}$ oral thrice daily & Initial CDI & - & D-I & $\begin{array}{l}\text { Non-antibiotic, toxin binding } \\
\text { polymer. Inferior to metronidazole } \\
\text { and vancomycin. }\end{array}$ \\
\hline
\end{tabular}


Table I (Continued)

\begin{tabular}{|c|c|c|c|c|c|}
\hline \multirow{2}{*}{$\begin{array}{l}\text { Antimicrobial/ } \\
\text { Non- } \\
\text { antimicrobial } \\
\text { agents }\end{array}$} & \multirow[t]{2}{*}{$\begin{array}{l}\text { Recommended } \\
\text { dosage and duration }\end{array}$} & \multirow[t]{2}{*}{ Role in CDI } & \multicolumn{2}{|c|}{$\begin{array}{l}\text { Current guidelines } \\
\text { recommendation }\end{array}$} & \multirow[t]{2}{*}{ Comments } \\
\hline & & & $\begin{array}{l}\text { SHEA-IDSA } \\
2010\end{array}$ & $\begin{array}{l}\text { ESCMID }^{21} \\
2014\end{array}$ & \\
\hline \multicolumn{6}{|c|}{ Current preventive options } \\
\hline Bezlotoxumab & $\begin{array}{l}10 \mathrm{mg} / \mathrm{kg} \text { intravenous } \\
\text { single dose along with } \\
\text { standard CDI antibiotic } \\
\text { therapy }\end{array}$ & $\begin{array}{l}\text { Prevention of recurrent } \\
\text { CDI }\end{array}$ & - & C-I & $\begin{array}{l}\text { Monoclonal antibody against } C \text {. } \\
\text { difficile toxin } B \text {. FDA approved for } \\
\text { use in prevention of } C D I \text { recurrence. }\end{array}$ \\
\hline $\begin{array}{l}\text { Probiotics } \\
\text { (Saccharomyces } \\
\text { boulardii, } \\
\text { Lactobacillus } \\
\text { rhamnosus GG) }\end{array}$ & & $\begin{array}{l}\text { Initial and Recurrent } \\
\mathrm{CDI}\end{array}$ & - & D-I & $\begin{array}{l}\text { Adjunct to the standard-of-care } \\
\text { antibiotic therapy. Insufficient data } \\
\text { to support its use in prevention of } \\
\text { CDI. Risk of fungemia in critically-ill } \\
\text { patients. }\end{array}$ \\
\hline \multicolumn{6}{|c|}{ Emerging treatment options } \\
\hline Cadazolid & $250 \mathrm{mg}$ oral twice daily & Phase III trial & - & - & $\begin{array}{l}\text { Non-absorbable antibiotic with } \\
\text { protein synthesis inhibitor activity } \\
\text { against } C \text {. difficile toxins and spores. }\end{array}$ \\
\hline Surotomycin & $250 \mathrm{mg}$ oral twice daily & $\begin{array}{l}\text { Phase III trial } \\
\text { (completed) }\end{array}$ & - & - & $\begin{array}{l}\text { Bactericidal activity against } C \text {. difficile. } \\
\text { Failed to meet non-inferiority criteria } \\
\text { vs vancomycin. }\end{array}$ \\
\hline Ridinilazole & $250 \mathrm{mg}$ oral twice daily & $\begin{array}{l}\text { Phase II trial } \\
\text { (completed) }\end{array}$ & - & - & $\begin{array}{l}\text { Targeted bactericidal activity against } \\
\text { C. difficile. }\end{array}$ \\
\hline $\begin{array}{l}\text { SER-I09 } \\
\text { (encapsulated } \\
\text { microbiota) }\end{array}$ & Orally administered & Phase II trial & - & - & $\begin{array}{l}\text { Restores normal microbiota. } \\
\text { Potential indication in prevention of } \\
\text { recurrent CDI. }\end{array}$ \\
\hline $\begin{array}{l}\text { RBX2660 } \\
\text { (microbiota } \\
\text { suspension) }\end{array}$ & Enema suspension & Phase II trial & - & - & $\begin{array}{l}\text { Restores normal microbiota. } \\
\text { Potential indication in severe or } \\
\text { recurrent CDI. }\end{array}$ \\
\hline \multicolumn{6}{|c|}{ Emerging preventive options } \\
\hline Immunoglobulins & $150-400 \mathrm{mg} / \mathrm{kg}$ & $\begin{array}{l}\text { Initial and recurrent } \\
\mathrm{CDI}\end{array}$ & - & $\begin{array}{l}\text { C-II } \\
\text { (Initial CDI) } \\
\text { D-I } \\
\text { (Recurrent CDI) }\end{array}$ & $\begin{array}{l}\text { Passive immunotherapy in CDI. } \\
\text { Randomized controlled trials in } \\
\text { progress. }\end{array}$ \\
\hline $\begin{array}{l}\text { Non-toxigenic } \\
\text { C. difficile strains } \\
\text { (VP 2062I) }\end{array}$ & & $\begin{array}{l}\text { Phase II trial } \\
\text { (completed) }\end{array}$ & - & - & $\begin{array}{l}\text { Substitute toxigenic } C \text {. difficile to non- } \\
\text { toxigenic form. Potential indication in } \\
\text { prevention of recurrent CDI. }\end{array}$ \\
\hline $\begin{array}{l}\text { Toxoid-based } \\
\text { conjugated } \\
\text { vaccines }\end{array}$ & & Phase II/III (completed) & - & - & $\begin{array}{l}\text { Immunization to promote production } \\
\text { of neutralizing antitoxin antibody for } \\
\text { primary prevention of } C D I \text {. }\end{array}$ \\
\hline Ribaxamase & $\begin{array}{l}75 \mathrm{mg} \text { oral four times } \\
\text { daily (dose per Phase } \\
\text { II trial) }\end{array}$ & Phase II trial & - & - & $\begin{array}{l}\text { Protection of gut microbiota by } \\
\text { prevention of antibiotic mediated gut } \\
\text { microbiota dysbiosis. Data limited to } \\
\text { the porcine gut model study. }\end{array}$ \\
\hline DAV-I32 & & Phase I trial & - & - & $\begin{array}{l}\text { Potential indication as prophylactic } \\
\text { treatment for prevention of CDI. } \\
\text { Acts by binding and neutralizing } \\
\text { antibiotics in the gut, retaining } \\
\text { normal microbiota. }\end{array}$ \\
\hline
\end{tabular}

Note: Guidelines recommendation to support use: A- Strong evidence, B- Moderate evidence, C- Marginal evidence, D- No evidence.

Abbreviations: CDI, Clostridium difficile infection; ESCMID, European Society of Clinical Microbiology and Infectious Diseases; FDA, US Food and Drug Administration; IDSA, Infectious Diseases Society of America; SHEA, Society for Healthcare Epidemiology of America.

exchange-mass spectrometry, and surface plasmon resonance tests confirmed the interaction of bezlotoxumab with the intact full-length of $C$. difficile toxin B and its peptides. $\mathrm{X}$-ray crystallography demonstrated Fab fragments of bezlotoxumab binding specifically to two epitopes within the N-terminal half of oligopeptide domains of toxin B. The binding results in complete neutralization of toxin $\mathrm{B}$ by directly blocking its carbohydrate binding pockets and 
thus preventing its attachment to the colonic mucosal cells. ${ }^{27}$ Other postulated mechanisms of neutralization of toxin B by bezlotoxumab include conformational change in toxin B masking its receptor binding sites, blocking cell adhesion via binding to alternative non-carbohydrate binding pockets. Bezlotoxumab showed no binding affinity to toxin A.

Bezlotoxumab is administered via intravenous route and animal studies have provided insight into the mechanism of antibody transport into the gut epithelium. Contrary to the previous belief, a study on murine and hamster models infected with CDI showed Fc receptor independent transport of antibodies into the gut epithelium. ${ }^{18}$ Consequently, an in vitro study performed on intestinal mucosal epithelium simulation model reinforced Fc independent paracellular transport of Fab fragments of antitoxin antibodies across the gut. ${ }^{18}$ The antibody transport was seen to be directly proportional to the presence of toxins in apical chamber of the intestinal epithelial cells. ${ }^{18}$ Thus, confirming that toxinmediated intestinal epithelial damage promotes the transport of antitoxin antibodies into the intestinal lumen.

\section{Pharmacokinetics (PK) and pharmacodynamics (PD)}

Bezlotoxumab is administered as a single $10 \mathrm{mg} / \mathrm{kg}$ intravenous dose infused over 60 minutes for the prevention of recurrent CDI. ${ }^{25}$ Each vial contains $1000 \mathrm{mg}$ of sterile, aqueous, preservative-free bezlotoxumab, diluted in $0.9 \%$ sodium chloride or $5 \%$ dextrose prior to infusion. ${ }^{26}$ Bezlotoxumab is approved for use only in the adult ( $\geq 18$ years of age) population while on concomitant anti-CDI therapy and has no established role as monotherapy agent or in treatment of $\mathrm{CDI} .{ }^{28}$ The precise timing of infusion of bezlotoxumab in correlation to the standard-of-care CDI therapy is undefined. In the Phase III trials, bezlotoxumab was generally administered an average of 3 days from the standard-of-care treatment. ${ }^{25}$ The dosing is based on the actual body weight. No dose adjustment is required in presence of hepatic impairment or renal dysfunction. The pharmacokinetic study showed the lack of effect of different population demographics (age, gender, race, albumin level, comorbidities) on effective concentration of bezlotoxumab. ${ }^{29}$ Administration of bezlotoxumab along with standard-of-care CDI therapy has no effect on its efficacy. Bezlotoxumab has a mean volume of distribution of 7.33 L and achieves a maximum concentration of $185 \mu \mathrm{g} / \mathrm{mL}$. In the Phase II trials, patients in the monoclonal antibody group had detectable levels of antitoxin $\mathrm{B}$ in the serum for $22 \pm 13$ days, after the initial infusion. ${ }^{30}$ Bezlotoxumab has an estimated long half-life of 19 days in humans with clearance at a rate of $0.317 \mathrm{~L} /$ day. It is cleared by protein catabolism into smaller peptides and amino acids. It is cleared rapidly in individuals with higher body weight. Bezlotoxumab acts directly on the toxin B and does not alter any metabolic enzymes or transporters. There is no in vivo or in vitro evidence of any drug-drug interactions or any teratogenic potential of bezlotoxumab. ${ }^{29}$

Higher concentration of bezlotoxumab was seen in the toxin-damaged intestinal lumen of $C$. difficile infected hamster models compared to controls. ${ }^{18}$ The $\mathrm{PK} / \mathrm{PD}$ relationship remains undetermined due to inability to quantify the precise concentration of bezlotoxumab in the serum or stool specimens. The required concentration of bezlotoxumab in the gut lumen to effectively inactivate toxin B is also unknown.

\section{Efficacy studies}

\section{Animal studies}

In vivo studies were performed in various animal models to evaluate the effectiveness of monotherapy or combination therapy of monoclonal antibodies against CDI. The results of these studies provided guidance in dosing and treatment strategy to perform future clinical trials in humans.

Studies conducted in animal models established the protective mechanism of antitoxin antibodies against CDI independent of its host effector functions.

A study conducted on murine models showed significantly lower intestinal epithelial cell wall damage, hemorrhage, necrosis, infiltration with neutrophils and apoptotic cells in models treated with combined monoclonal antibodies (actoxumab-bezlotoxumab) compared to untreated models. ${ }^{13}$ The antibodies were also deemed to provide indirect protection to the colonic wall by negating toxin-mediated damage. Unlike the currently available therapies for CDI, antitoxin antibodies demonstrated similar neutralization and protective mechanism of action against the hypervirulent (NAP1/ $\mathrm{BI} / 027)$ C. difficile strains. $^{13}$

Hamsters are the standard models used for in vivo analysis during the study of CDI. Hamsters develop severe CDI as compared to humans but its therapeutic response to treatment serves it as a suitable model for analysis. ${ }^{15}$ Babcock et al conducted two experiments on hamster models to demonstrate the efficacy of monoclonal antitoxin antibodies in CDI. ${ }^{31}$ The initial study was performed to assess the mortality benefit in hamster model with primary CDI. Primary CDI was induced in the hamster models by administration of clindamycin at least 24 hours prior to the orogastric instillation of $C$. difficile spores. Intraperitoneal administration of antitoxin A antibody $(50 \mathrm{mg} / \mathrm{kg} /$ day $)$ and antitoxin B antibody $(10-50 \mathrm{mg} / \mathrm{kg} /$ day $)$ 
alone or as a combination therapy was performed for 4 days prior to the administration of $C$. difficile spores. Traditionally without antitoxin antibodies, $100 \%$ mortality was seen in all the hamster models due to severe CDI. The study showed $45 \%$ reduction in mortality in the hamster models treated with combination monoclonal antibodies. In the second part of the study, the efficacy of antitoxin antibodies was evaluated in the hamster models with relapse of CDI. Hamster models with CDI relapse were challenged with $C$. difficile spores and simultaneously initiated on vancomycin treatment. In the study, models received either vancomycin alone or in combination with monoclonal antitoxin antibody A or B or both A and B from day 2-6 post-spore challenge. In comparison to vancomycin monotherapy, treatment with vancomycin and combination monoclonal antibodies demonstrated early (day 6) and late (day 10) protection against mortality from CDI. The early and late survival rates in the hamster models increased by $38 \%$ and $22 \%$, respectively. In both primary and relapse models of CDI, treatment with antitoxin B monoclonal antibody alone did not show any survival benefit. Based on quantitative analysis of protective monoclonal antibody levels in the hamster sera, administration of a single dose of $10 \mathrm{mg} / \mathrm{kg}$ of monoclonal antibodies was recommended in the management of CDI in humans.

A similar in vivo study was performed by Dzunkova et al in mice models infected with CDI. ${ }^{32}$ Mice models were initially treated with clindamycin, then treated with vancomycin antibiotic and/or monoclonal antibodies followed by inoculation with $C$. difficile spores. Models were divided into four treatment groups; combination therapy alone (actoxumab-bezlotoxumab), combination of monoclonal antibodies and vancomycin, vancomycin alone, and placebo. Mice models with severe CDI were followed until end of the study (day 28). An $80 \%$ survival rate was seen in the mice models that received combination of vancomycin and monoclonal antibodies. Treatment group receiving only actoxumab-bezlotoxumab showed $90 \%$ reduction in CDI symptoms during the entire study period. On the contrary, the mice models treated with vancomycin alone had mortality of $60 \%$ and placebo group had $100 \%$ mortality by day 4 of the study period. Further intestinal microbial diversity analysis in mice models elucidated distinct characteristic of monoclonal antibodies to help restore the original gut microbiota, not observed with vancomycin treatment.

A comparative study was conducted in hamster and mice CDI-infected models to evaluate the effectiveness of vancomycin and monoclonal antibodies in prevention of recurrent CDI. ${ }^{15}$ The study showed functionality of vancomycin against
CDI to be limited to the duration of therapy. Vancomycin was associated with simultaneous damage to the gut microbiota resulting in a delayed recovery and higher predisposition to CDI recurrence. Monoclonal antibodies preserved the gut microbiota and were postulated to neutralize the toxin release from new as well as persistent $C$. difficile spores, demonstrating its potency in prevention of recurrent CDI.

\section{Human studies}

Phase I trial: a total of five Phase I trials were conducted to assess the effects of monoclonal antibodies in healthy subjects. All the trials included administration of bezlotoxumab as monotherapy or as part of combination therapy except one trial. Only four trials of interest are discussed in this section. ${ }^{33}$

A Phase I dose escalation study (P020) was performed enrolling 60 healthy adult volunteers; six received actoxumab, 30 received bezlotoxumab, and 24 received combination of monoclonal antibodies. This was the only Phase I study to evaluate independent bezlotoxumab PK after administration of ascending drug doses ranging from 0.3 to $20 \mathrm{mg} / \mathrm{kg}$. Unfortunately, the non-specific bioanalytical assay used in the study failed to distinguish between the endogenous antitoxin $\mathrm{B}$ antibodies and bezlotoxumab. Thus, due to lack of validity, the PK and immunogenicity analysis from this study were not taken into consideration.

A Phase I open-label multi-dose study (P004) was conducted to evaluate the $\mathrm{PK}$ and immunogenicity analysis of monoclonal antibodies against toxin $\mathrm{A}$ and $\mathrm{B}$ in healthy adults. A total of 30 subjects were included receiving initial $10 \mathrm{mg} / \mathrm{kg}$ dose of actoxumab and bezlotoxumab as a 1-hour infusion, followed by repeat second dose on day 85 . Another Phase I double-blind, randomized placebo-controlled single dose study (P005) was performed in 35 healthy adult subjects. Subjects received a $10 \mathrm{mg} / \mathrm{kg}$ dose of actoxumab and bezlotoxumab over 1-hour infusion. Pharmacokinetic analysis was performed in 23 subjects on day 22 and 12 subjects on day 85 . This was the primary study to evaluate the PK and tolerability of monoclonal antibodies administered as a $250 \mathrm{~mL}$ infusion over 1-hour duration. Similar to other Phase I trials, a double-blind, randomized placebo-controlled trial (P006) was conducted in 19 healthy Japanese male volunteers. Subjects were administered a single dose of actoxumab and bezlotoxumab at 10 or $20 \mathrm{mg} / \mathrm{kg}$ dose in a $250 \mathrm{~mL}$ infusion.

The results of all four Phase I trials showed bezlotoxumab to be a safe and well-tolerated drug when infused as monotherapy or combination therapy. No serious adverse events were seen in the healthy volunteers. The PK analysis showed 
similar parameters in the Japanese and the non-Japanese volunteers. The drug clearance was independent of administered dose. Immunogenicity analysis in the trials did not detect any serum anti-bezlotoxumab antibodies. The Phase I studies identified pharmacokinetic characteristics of bezlotoxumab to be similar to other monoclonal antibodies and established $10 \mathrm{mg} / \mathrm{kg}$ as the recommended infusion dosage.

Phase II trial: a Phase II randomized double-blind placebo-controlled trial was conducted across multiple centers in the USA and Canada. ${ }^{30}$ The trial enrolled CDI patients with ongoing diarrhea while on vancomycin or metronidazole treatment. Patients were randomized to receive either a single intravenous infusion of $10 \mathrm{mg} / \mathrm{kg}$ of fully human monoclonal antibody against $C$. difficile toxin A (CDA1) and toxin B (CDB1) or placebo. A total of 200 patients were included in the study, 101 in monoclonal antibody group and 99 in placebo group. Patients received an average of 3 days of antibiotic therapy ( $70 \%$ on metronidazole and $30 \%$ on vancomycin) prior to enrollment in both groups. Overall, patients in the monoclonal antibody group had significantly lower CDI recurrence rate (7\%) compared to placebo group $(25 \%)$, at the end of antibiotic therapy or after resolution of diarrhea. The subjects with recurrent CDI in the monoclonal antibody group were known to be at high risk for recurrence (old age and higher comorbidities) during enrollment. No differences were observed in the hospital length of stay and time to diarrhea resolution in both groups.

Phase III trial: two Phase III randomized placebocontrolled trials were conducted across the globe to analyze the effect of administering specific monoclonal antibodies and combined monoclonal antibodies in patients with CDI. ${ }^{25}$ A total of 2599 patients with CDI on treatment with vancomycin $(48 \%)$ or metronidazole $(47 \%)$ or fidaxomicin (4\%) were included in the study. Patients were randomized to receive $10 \mathrm{mg} / \mathrm{kg}$ single-dose IV infusion of bezlotoxumab ( $\mathrm{n}=781)$, actoxumab-bezlotoxumab $(\mathrm{n}=773)$, actoxumab alone $(n=232)$ or placebo $(n=773)$. The study results showed significantly lower rates of CDI recurrence in the bezlotoxumab group (17\%) and combination monoclonal antibodies group (15\%) compared to placebo (27\%). The initial cure rate was similar in the bezlotoxumab $(80 \%)$, bezlotoxumab-actoxumab (73\%) and placebo groups $(80 \%)$ and the sustained cure rates at the end of 12 weeks were slightly higher in bezlotoxumab arm (64\%) compared to placebo $(54 \%)$. The majority of the recurrences $(71 \%)$ occurred within the first month after monoclonal antibody infusion. The choice of antibiotic therapy for treatment of CDI did not influence the treatment outcomes in both groups. The CDI recurrence rate in the study groups was similar in patients of different geographic locations and independent of hospitalization status during the enrollment.

\section{High-risk population}

The Phase II and III trials analyzed the effect of bezlotoxumab in a population at high risk of recurrent CDI such as those with presence of previous history of CDI and BI/NAP1/027 strain. ${ }^{25,30}$

In a Phase II trial, $31 \%$ of the population had a previous history of CDI and treatment with combination monoclonal antibodies resulting in significantly lower rate of recurrence (7\%) compared to placebo (38\%). Likewise, in a Phase III trial, in patients with one or more risk factors for CDI (77\%), treatment with bezlotoxumab showed lower rates of CDI recurrence compared to placebo (17\% vs 30\%).

An in vitro study on Vero cells showed lower binding affinity of bezlotoxumab to toxin B of ribotypes 027 and 078 in comparison to other ribotypes. ${ }^{34}$ Administration of a higher than normal concentration of bezlotoxumab was required to neutralize toxin $\mathrm{B}$ of these hypervirulent ribotype strains. Approximately $29 \%$ of patients enrolled in the Phase II trial had detectable epidemic BI/NAP1/027 strain. Treatment of epidemic strain with combination monoclonal antibodies resulted in lower recurrence rate $(8 \%)$ compared to placebo $(32 \%)$, however the difference failed to achieve statistical significance $(p=0.06) .{ }^{30}$ In the Phase III trial, the 027 strain of $C$. difficile was present in $18 \%$ of patients. Treatment with combination monoclonal antibodies had higher impact in decreasing the risk of recurrent CDI in comparison to bezlotoxumab alone or placebo ( $12 \%$ vs $24 \%$ vs $34 \%$ recurrence). Overall, in the Phase III trial, patients at high risk of recurrent CDI or adverse outcomes from CDI had lower recurrence rates in the bezlotoxumab (17\%) and actoxumab-bezlotoxumab (16\%) group compared to placebo $(30 \%){ }^{25}$

\section{Indication and approval}

Based on Phase III clinical trial results, the US Food and Drug administration (FDA) approved the use of bezlotoxumab in prevention of recurrent CDI in October 2016. ${ }^{28}$ Bezlotoxumab is indicated for use in adult patients ( $\geq 18$ years of age) at high risk of recurrence, undergoing the standard-of-care antimicrobial treatment for CDI. Patients with CDI in the previous 6 months, severe CDI, aged $\geq 65$ years, ongoing antibacterial therapy, immunocompromising conditions and CDI due to hypervirulent ribotype strains 027,078 or 244 were defined to be at high risk for recurrence. ${ }^{17,33}$ Bezlotoxumab is not approved for use in the clinical cure of CDI. 


\section{Resistance}

Currently, there is no evidence on development of resistance to bezlotoxumab. The Phase II and III randomized trials performed serum studies to detect anti-bezlotoxumab antibodies. Both the trials showed no detectable anti-monoclonal antibody levels..$^{25,30}$ In addition, in vitro studies also did not demonstrate any evidence of anti-bezlotoxumab antibody production.

\section{Safety and precautions}

Studies exclusively analyzing the safety and efficacy of bezlotoxumab have not been conducted. Most of the adverse events related to bezlotoxumab are based on reports from the Phase II and III randomized controlled trials. ${ }^{25,30}$ Overall, the adverse events secondary to monoclonal antibody therapy were non-serious and did not differ compared to placebo. Infusion-related reactions were usually mild. In the Phase III trial, possible acute hypersensitivity reaction on the same day or a day after infusion was reported in 10\% (81/786) of the participants receiving bezlotoxumab compared to $7.6 \%$ (59/781) receiving placebo. During the follow-up period, nausea, diarrhea, and headache were the most common adverse events reported. Serious adverse events were rare with no significant difference between treatment and placebo arm, except for significantly higher hypotension events in the placebo group in the Phase II trial. There was no difference in the 3-month mortality incidences in both groups.

There was no effect of bezlotoxumab on QTc interval. Precaution is advised prior to usage of bezlotoxumab in patients with heart failure. ${ }^{33}$ The Phase III clinical trials reported higher adverse events in patients with preexisting congestive heart failure (CHF) in bezlotoxumab treatment arm. During the 12-week study period, higher CHF and deaths occurred in bezlotoxumab (CHF 13\%, death 19.5\%) arm compared to the placebo arm (CHF 5\%, death 12.5\%). Bezlotoxumab should be used cautiously in patients with underlying CHF, use is advised only when the benefit outweighs risk.
Toxicology studies conducted on mice did not demonstrate any clinical or histological evidence of toxicity related to bezlotoxumab in comparison to placebo, even at higher than recommended concentrations. ${ }^{33}$

\section{Cost-estimate}

A single $100 \mathrm{mg}$ vial of bezlotoxumab costs US $\$ 4,500 .{ }^{26}$ An unpublished post hoc analysis on bezlotoxumab showed lower 30-day CDI-related hospital readmissions (4\% with bezlotoxumab vs $9.6 \%$ with placebo) as well as all-cause readmissions ( $23 \%$ with bezlotoxumab vs $26.9 \%$ with placebo). ${ }^{35}$ No published studies have been conducted to analyze the cost-effectiveness of administering bezlotoxumab along with anti-CDI therapy.

\section{Uncertainties and future perspectives}

Bezlotoxumab is the first FDA-approved monoclonal antibody active against $C$. difficile toxin $\mathrm{B}$. All the in vivo, in vitro human and animal research studies have established its effectiveness in the prevention of recurrent CDI. Numerous uncertainties challenge the clinical use of bezlotoxumab. The rising health care expenditure and lack of evidence on the pharmacoeconomic benefits of addition of bezlotoxumab to the standard anti-CDI therapy might be the limiting factor for the real-time usage of this high-cost drug. Universal approval of any drug in management of disease relies profoundly on strong recommendations in the standard guidelines. The level of recommendation for bezlotoxumab as a preventive therapy option in the USA and the European CDI guidelines is currently unknown. Numerous antibiotic therapies (surotomycin, cadazolid) and prophylactic agents (immunoglobulin vaccines, biologic agents) against $\mathrm{CDI}$ are currently in the pipeline, challenging the shelf-life of bezlotoxumab. Table 2 highlights the important benefits and risks associated with bezlotoxumab.

Table 2 Summary of benefits and risks of bezlotoxumab in Clostridium difficile infection

\begin{tabular}{|c|c|}
\hline Advantages/benefits & Disadvantages/risks \\
\hline I. Approved for use in prevention of recurrent CDI & I. No efficacy in clinical cure of CDI \\
\hline 2. One-time dose administration & 2. Requires intravenous administration \\
\hline 3. Restores gut microbiota & 3. Lack of specific time-interval for infusion in correlation to the standard- \\
\hline 4. Effective against geographically diverse $C$. difficile strains and against & of-care CDI therapy \\
\hline hypervirulent strain of $C$. difficile (BI/NAPI/027) & 4. Unknown serum target levels to achieve effective intestinal luminal \\
\hline 5. No need for dose adjustment, lacks drug-drug interaction & concentration against antitoxin B \\
\hline 6. Minimal serious adverse events & 5. Limited data on effectiveness as monotherapy in prevention of CDI \\
\hline \multirow[t]{2}{*}{ 7. No evidence of resistance to treatment } & 6. High-cost drug with no data on cost-effectiveness \\
\hline & 7. No published data on real-world experience to validate its efficacy \\
\hline
\end{tabular}

Abbreviation: CDI, Clostridium difficile infection. 


\section{Conclusion}

Bezlotoxumab is an effective monoclonal antibody against C. difficile toxin B reducing recurrent CDI by $40 \%$ at the end of 12 weeks in comparison to placebo. A single infusion of safe and well-tolerated bezlotoxumab is easy to administer, however cost-effectiveness analysis has not been performed yet to validate usage of this high-priced drug. In the era of finite choices for treatment of recurrent CDI, bezlotoxumab emerges as a compelling rescue therapy for prevention of recurrent CDI. Further data are needed to establish its clinical effectiveness.

\section{Disclosure}

The authors report no conflicts of interest in this work.

\section{References}

1. Dubberke ER, Carling P, Carrico R, et al. Strategies to prevent Clostridium difficile infections in acute care hospitals: 2014 update. Infect Control Hosp Epidemiol. 2014;35 Suppl 2:S48-65.

2. Cohen SH, Gerding DN, Johnson S, et al. Clinical practice guidelines for Clostridium difficile infection in adults: 2010 update by the society for healthcare epidemiology of America (SHEA) and the infectious diseases society of America (IDSA). Infect Control Hosp Epidemiol. 2010;31(5):431-455.

3. Lessa FC, Mu Y, Bamberg WM, et al. Burden of Clostridium difficile infection in the United States. $N$ Engl J Med. 2015;372(9): 825-834.

4. Dubberke ER, Olsen MA. Burden of Clostridium difficile on the healthcare system. Clin Infect Dis. 2012;55(Suppl 2):S88-S92.

5. Desai K, Gupta SB, Dubberke ER, Prabhu VS, Browne C, Mast TC. Epidemiological and economic burden of Clostridium difficile in the United States: estimates from a modeling approach. BMC Infect Dis. 2016;16:303.

6. Sheitoyan-Pesant C, Abou Chakra CN, Pepin J, Marcil-Heguy A, Nault $\mathrm{V}$, Valiquette L. Clinical and healthcare burden of multiple recurrences of Clostridium difficile Infection. Clin Infect Dis. 2016;62(5): 574-580.

7. Awad MM, Johanesen PA, Carter GP, Rose E, Lyras D. Clostridium difficile virulence factors: insights into an anaerobic spore-forming pathogen. Gut Microbes. 2014;5(5):579-593.

8. Di Bella S, Ascenzi P, Siarakas S, Petrosillo N, di Masi A. Clostridium difficile toxins $\mathrm{A}$ and $\mathrm{B}$ : insights into pathogenic properties and extraintestinal effects. Toxins (Basel). 2016;8(5).

9. Taylor CP, Tummala S, Molrine D, et al. Open-Label, dose escalation phase I study in healthy volunteers to evaluate the safety and pharmacokinetics of a human monoclonal antibody to Clostridium difficile toxin A. Vaccine. 2008;26(27-28):3404-3409.

10. Lyras D, O'Connor JR, Howarth PM, et al. Toxin B is essential for virulence of Clostridium difficile. Nature. 2009;458(7242): 1176-1179.

11. Carter GP, Rood JI, Lyras D. The role of toxin A and toxin B in Clostridium difficile-associated disease: past and present perspectives. Gut Microbes. 2010;1(1):58-64.

12. McDonald LC, Killgore GE, Thompson A, et al. An epidemic, toxin gene-variant strain of Clostridium difficile. N Engl J Med. 2005;353(23): 2433-2441.

13. Yang Z, Ramsey J, Hamza T, et al. Mechanisms of protection against Clostridium difficile infection by the monoclonal antitoxin antibodies actoxumab and bezlotoxumab. Infect Immun. 2015;83(2):822-831.
14. Vedantam G, Clark A, Chu M, McQuade R, Mallozzi M, Viswanathan VK. Clostridium difficile infection: toxins and non-toxin virulence factors, and their contributions to disease establishment and host response. Gut Microbes. 2012;3(2):121-134.

15. Warn P, Thommes P, Sattar A, et al. Disease progression and resolution in rodent models of Clostridium difficile Infection and impact of antitoxin antibodies and vancomycin. Antimicrob Agents Chemother. 2016;60(11):6471-6482.

16. Humphreys DP, Wilcox MH. Antibodies for treatment of Clostridium difficile infection. Clin Vaccine Immunol. 2014;21(7):913-923.

17. Gupta SB, Mehta V, Dubberke ER, et al. Antibodies to toxin B are protective against Clostridium difficile infection recurrence. Clin Infect Dis. 2016;63(6):730-734.

18. Zhang Z, Chen X, Hernandez LD, et al. Toxin-mediated paracellular transport of antitoxin antibodies facilitates protection against Clostridium difficile infection. Infect Immun. 2015;83(1):405-416.

19. Koon HW, Shih DQ, Hing TC, et al. Human monoclonal antibodies against Clostridium difficile toxins $\mathrm{A}$ and $\mathrm{B}$ inhibit inflammatory and histologic responses to the toxins in human colon and peripheral blood monocytes. Antimicrob Agents Chemother. 2013;57(7):3214-3223.

20. Johnson S, Louie TJ, Gerding DN, et al. Vancomycin, metronidazole, or tolevamer for Clostridium difficile infection: results from two multinational, randomized, controlled trials. Clin Infect Dis. 2014;59(3):345-354.

21. Debast SB, Bauer MP, Kuijper EJ; European Society of Clinical Microbiology and Infectious Diseases. European Society of Clinical Microbiology and Infectious Diseases: update of the treatment guidance document for Clostridium difficile infection. Clin Microbiol Infect. 2014; 20(Suppl 2):1-26.

22. Cornely OA, Nathwani D, Ivanescu C, Odufowora-Sita O, Retsa P, Odeyemi IA. Clinical efficacy of fidaxomicin compared with vancomycin and metronidazole in Clostridium difficile infections: a metaanalysis and indirect treatment comparison. J Antimicrob Chemother. 2014;69(11):2892-2900.

23. Martin J, Wilcox M. New and emerging therapies for Clostridium difficile infection. Curr Opin Infect Dis. 2016;29(6):546-554.

24. Kociolek LK, Gerding DN. Breakthroughs in the treatment and prevention of Clostridium difficile infection. Nature reviews Gastroenterology \& Hepatology. 2016;13(3):150-160.

25. Wilcox MH, Gerding DN, Poxton IR, et al. Bezlotoxumab for prevention of recurrent Clostridium difficile infection. $N$ Engl $J$ Med. 2017;376(4):305-317.

26. Chapin RW, Lee T, McCoy C, Alonso CD, Mahoney MV. Bezlotoxumab: could this be the answer for Clostridium difficile recurrence? Ann Pharmacother. 2017;51(9):804-810.

27. Orth P, Xiao L, Hernandez LD, et al. Mechanism of action and epitopes of Clostridium difficile toxin B-neutralizing antibody bezlotoxumab revealed by X-ray crystallography. J Biol Chem. 2014;289(26):18008-18021.

28. Mullard A. FDA approves antitoxin antibody. Nature reviews Drug discovery. 2016;15(12):811

29. Zinplava (bezlotoxumab) [prescribing information]. Whitehouse Station. NJ: Merck \& Co, Inc; 2016

30. Lowy I, Molrine DC, Leav BA, et al. Treatment with monoclonal antibodies against Clostridium difficile toxins. NEngl J Med. 2010;362(3):197-205.

31. Babcock GJ, Broering TJ, Hernandez HJ, et al. Human monoclonal antibodies directed against toxins $\mathrm{A}$ and $\mathrm{B}$ prevent Clostridium difficileinduced mortality in hamsters. Infect Immun. 2006;74(11):6339-6347.

32. Dzunkova M, D'Auria G, Xu H, et al. The monoclonal antitoxin antibodies (actoxumab-bezlotoxumab) treatment facilitates normalization of the gut microbiota of mice with Clostridium difficile infection. Front Cell Infect Microbiol. 2016;6:119.

33. US Food and Drug Administration. FDA Briefing Document Bezlotoxumab Injection. BLA 761046: bezlotoxumab injection. FDA; 2016. Available from: https://www.fda.gov/downloads/advisorycommittees/ committeesmeetingmaterials/drugs/anti-infectivedrugsadvisorycommittee/ucm505290.pdf. Accessed December 5, 2017. 
34. Hernandez LD, Racine F, Xiao L, et al. Broad coverage of genetically diverse strains of Clostridium difficile by actoxumab and bezlotoxumab predicted by in vitro neutralization and epitope modeling. Antimicrob Agents Chemother. 2015;59(2):1052-1060.
35. Golan Y, Dubberke E, Hanson M, et al. Bezlotoxumab (BZO) decreases recurrence and is associated with a reduction in 30-day Clostridium difficile infection-associated readmissions in hospitalized patients with CDI. ASM Microbe 2016; Boston. Abstract 449.

\section{Publish your work in this journal}

Biologics: Targets and Therapy is an international, peer-reviewed journa focusing on the patho-physiological rationale for and clinical application of Biologic agents in the management of autoimmune diseases, cancers or other pathologies where a molecular target can be identified. This journal is indexed on PubMed Central, EMBase, and Scopus.
Dovepress

The manuscript management system is completely online and includes a very quick and fair peer-review system, which is all easy to use. Visit http://www.dovepress.com/testimonials.php to read real quotes from published authors.

Submit your manuscript here: https://www.dovepress.com/biologics-targets-and-therapy-journal 